\title{
Effect of supplemental oxygen on native blood and myocardial MOLLI T1 relaxation times
}

\author{
James Goldfarb*, Kathleen Gliganic, Nathaniel Reichek \\ From 18th Annual SCMR Scientific Sessions \\ Nice, France. 4-7 February 2015
}

\begin{abstract}
Background
Magnetic resonance (MR) T1 relaxation time measurements are increasingly used for myocardial tissue characterization. Significant differences in native and gadolinium-enhanced measurements have been associated with ischemic and non-ischemic cardiomyopathies, myocardial fat deposition, fibrosis and edema as well as regional and global ventricular functional parameters.

Supplemental oxygen is often given to cardiac MR patients for improved breatholding. High flow supplemental oxygen with a non-rebreather mask is reported to reduce both myocardial and blood $\mathrm{T} 1$ relaxation times and has been studied with HASTE and FLASH T1 relaxation measurements for the optimization of MR ventilation scanning. The primary mechanism is dissolved oxygen acting as a paramagetic contrast agent. Conversely other reports show an increase of blood $\mathrm{T} 1$ times with increasing oxygen saturation. We studied the effect of supplemental oxygen on myocardial and blood T1 relaxation times using a well-documented T1 MOdified Look-Locker Imaging (MOLLI) protocol.
\end{abstract}

\section{Methods}

Twelve healthy subject without respiratory or cardiac disease (age: $47.4 \pm 5.3$ years; 6 male) were studied at 1.5T using MOLLI T1 mapping (TE/TE= 2.8/1.2 ms; 3(3) -5; 2 inversions, 3 heartbeat rest period; TI start $=120$ $\mathrm{ms}$; TI increment $=120 \mathrm{~ms} ; 3$ parameter curve fitting). Images were acquired in the four chamber view. Five measurements spaced by 10 minutes were performed with supplemental oxygen supplied by nasal cannula and a non-reberather mask alternating with room air (M1: Room air, M2: nasal oxygen (2 l/m), M3: Room air, M4: non-rebreather mask (15 l/m), M5: room air).

Research and Education, St Francis Hospital, Roslyn, NY, USA
Regions-of-interest were drawn for T1 measurements in the boodpool of each ventricle and atria as well as septal myocardium. The effects of supplemental oxygen were investigated statistically using a mixed model analysis of variance.

\section{Results}

Study results are displayed in Figure 1. In contrast to previously published reports, there was no difference between myocardial $\mathrm{T} 1$ relaxation times; $\mathrm{p}=.28$ with supplemental oxygen. There was a significant difference between blood T1 relaxation times; $\mathrm{p}<0.001$. Left ventricular and atrial T1 bloodpool relaxation times were significantly reduced using the non-rebreather mask and could be easily visualized in source T1 maps (Figure 2). There was no detected change in right atrial or ventricular bloodpool T1 times with supplemental oxygen, $\mathrm{p}>0.05$.

\section{Conclusions}

Use of supplemental oxygen can change measured MR T1 relaxation values. As measured using a well-documented MOLLI T1 protocol, there are significant changes in left

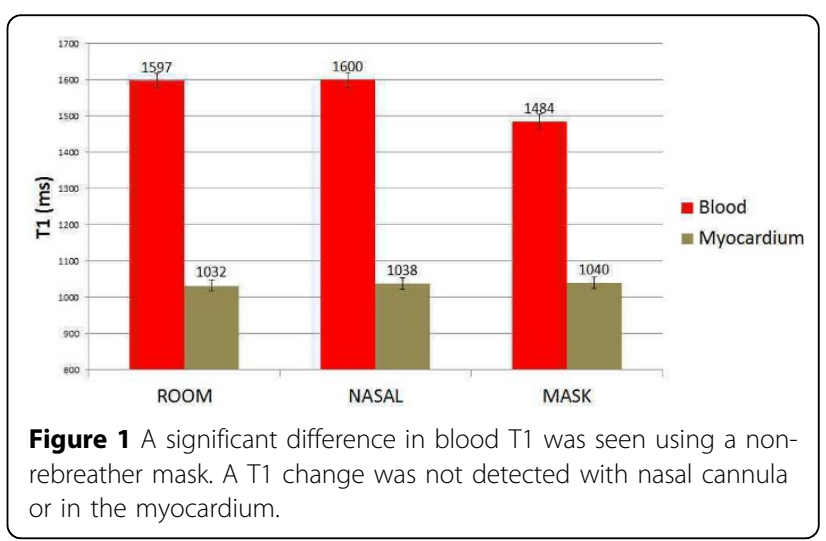




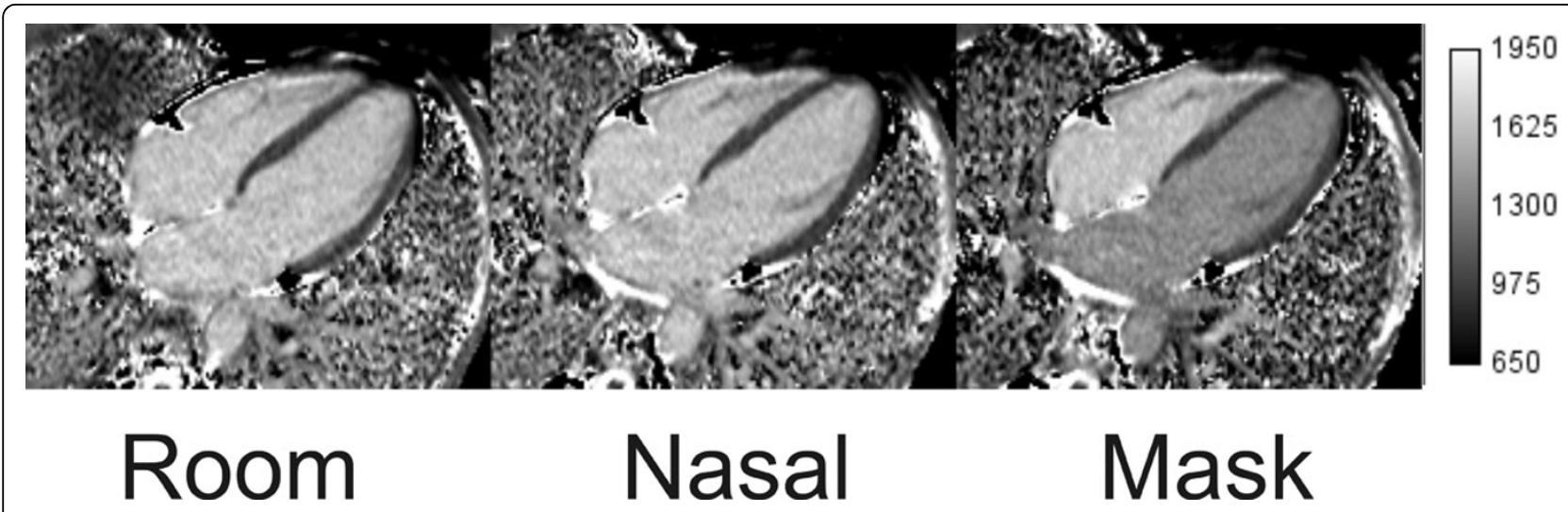

Figure 2 Native T1 maps with the subject breathing room air (ROOM), $2 \mathrm{l} / \mathrm{m}$ flow with nasal canula (NASAL) and $15 \mathrm{l} / \mathrm{m}$ with a non-rebreather mask (MASK). Reduced blood T1 with the non-rebreather mask can be visualised in the left side of the heart.

ventricular and atrial T1 relaxation times with supplemental oxygen supplied by a non-rebreather mask. We did not detect a change in oxygen supplied by nasal cannula. Additionally, myocardial, right atrial and ventricular bloodpool T1 relaxation times did not change with supplemental oxygen. If supplemental oxygen is used, one can measure blood relaxation times from the right side of the heart as they are unaffected.

Published: 3 February 2015

doi:10.1186/1532-429X-17-S1-W32

Cite this article as: Goldfarb et al:. Effect of supplemental oxygen on

native blood and myocardial MOLLI T1 relaxation times. Journal of Cardiovascular Magnetic Resonance 2015 17(Suppl 1):W32.
Submit your next manuscript to BioMed Central and take full advantage of:

- Convenient online submission

- Thorough peer review

- No space constraints or color figure charges

- Immediate publication on acceptance

- Inclusion in PubMed, CAS, Scopus and Google Scholar

- Research which is freely available for redistribution 